Riga, Latvia, May 7-8, 2021

\title{
HIGHER EDUCATION CHALLENGES CAUSED BY COVID-19
}

\section{Liliia Vinnikova $^{1}$}

DOI: https://doi.org/10.30525/978-9934-26-076-6-12

COVID-19 has changed our lives drastically in all main activity domains. People are facing a number of challenges caused by COVID-19 including education domain as well.

Educators are trying to cope with approaching challenges, which have been complicated by the fungal development of digital approach to learning process.

As a result, educators are reviewing the set of pedagogical tools to maintain student motivation domain.

First, we should take into account the fact that level of learning motivation has dropped that is revealed by our general observations and the questionnaires conducted among Borys Grinchenko Kyiv University students.

The analyses of the mentioned above research shows that student motivation sphere has had a harsh effect, albeit the educators' efforts.

It can be partially explained by the general tiredness at the end of the academic year as well as the lack of face-to-face communication.

What is more, the role of the modern educator as a facilitator and career planner has become more demanding due to great responsibility the society has delegated to professionals who work in the educational domain.

One of the educational objectives is to enable language learners to become professionals and be able to be flexible and resistant under the conditions of constantly changing environment. We, educators, have no choice but adopt appropriate approaches, which could help our learners grow, become resistant and learn to find the ways out more effectively.

Another challenge we are facing these days is new working conditions when the overwhelming majority of class time is dedicated to working in the cyber space.

Thus, our task is to create a kind of community where every member is ready to give a helping hand to each other and give a vivid example or cooperation and interpersonal skills to our students.

Besides, we can't but mention the necessity of fostering a sense of community in classes and promoting greater communication between students. Using different tools and methods, we can reduce the feeling of distance and isolation the students can experience nowadays.

We should also pay attention to the delivering successful online learning experience educators have already gained all over the world. It goes without

\footnotetext{
${ }^{1}$ Borys Grinchenko Kyiv University, Ukraine
} 
saying that the ways for online delivery are both similar and different to other learning modes.

The process of Design Thinking and empathy of a learner can be considered as an approach to effective learning.

The Global pandemic has influenced all the aspects of higher education. Nowadays the steady increase in demand for different educational programmes has led to the great variety of choices in learning content and the institutions, which can offer international higher education services.

Thus, transnational higher education appeared. Such changes were about to happen even before the pandemic struck. It means that now educational establishments are competing to attract and to keep their students.

All types of educational institutions, public and private, have taken up a challenge and reacted to the opportunities all over the world. As a result, innovative teaching and learning initiatives are being implemented thoroughly as well as new interactive learning platforms.

Furthermore, students are searching virtual mobility opportunities to study at any time. They also demand their teachers to drive out inequality. The key to this demand can be collaboration in transnational education.

One of the most important teacher's tasks is to provide the process of learning, but it has become even more challenging as we have changed the traditional way of knowledge delivering to remote online one.

In this case we are facing another issue - that is assessment. Nowadays we use computer-based testing to assess the student's skills. Artificial intelligence in language assessment can be the solution to this problem. The old language assessment models must be replaced by the bias-free automated assessments, which are more appropriate and fair to the student. And this assessment seems to help provide solutions to problems which language testing has had for years or the issues which have been ignored.

Educators should think over the assessment strategy as well. We must shift from traditional assessment such as closed books or time-limited examinations, to remote assessment and a variety of assessment online tools suggested by a number of learning platforms such as MEL, where the assessment is done automatically and the role of mentor is shifted to a learning facilitator [1, p. 40].

To sum it up, despite the short-term, medium-term and long-term challenges caused by COVID-19 in higher education, educators are struggling to overcome them by turning areas of weakness into strong points.

\section{References:}

1. Prokopchuk M. M. (2020). Iz dosvidu vprovadzhennia zmishanoho navchannia pry vyvchenni anhliiskoi movy za profesiinym spriamuvanniam [Blended learning approach to English for specific purposes implementation experience]. International Scientific Journal «Internauka», vol. 6(86), no. 71, pp. 39-41. 